\title{
Enhancing Quality in EAP Teaching and Learning: A Case Study of Selected Ghanaian Higher Educational Institutions
}

\author{
Solomon Ali Dansieh \\ Senior Lecturer, Language and Communication, Department of General and Liberal Studies, Ghana \\ sdansieh@yahoo.com
}

\begin{abstract}
The pervasiveness and compulsoriness of the English for Academic Purposes (EAP) course in tertiary education environments in Ghana is such that irrespective of first-year students' course offerings they must of necessity take it, even if for a short period. This makes it imperative that the quality assurance principles for enhancing its teaching and learning be examined. The object of this study has been to explore and compare the application of quality assurance principles to the teaching and learning of EAP in four higher education institutions in Ghana with the aim of identifying: (a) how context-specific QA systems work in the case study institutions; (b) what is being done differently there and (c) to offer suggestions for quality enhancement and replication elsewhere. The study asserts that since every tertiary-level course in Ghana is taught in English, assuring the quality of English language teaching and learning would naturally have a "multiplier effect" on the quality of the other courses. Findings of this research were derived largely from a student survey and, to a lesser extent, from interviews with senior members and subject lecturers at the case study institutions. Institutional context, quality culture, quality assurance mechanisms, pedagogy, and curriculum designs of the case study institutions were found to be very similar. Through its cross-case analysis of QA strategies in the public and private sectors of higher education in Ghana, the study contributes to the identification of the differences between the two sectors as regards the enhancement of the quality of EAP teaching and learning.
\end{abstract}

Keywords: English for Academic Purposes; quality assurance; quality enhancement; pervasiveness; compulsoriness.

\section{INTRODUCTION}

Today, more is expected of tertiary students from English-speaking countries like Ghana, where English is the medium of instruction, to possess some minimum global competence in their reading, writing, listening and speaking skills in academic and workplace communication. Whether it is in the public or market-driven private sector of HE, demand for quality tertiary education 'products' by key stakeholders of tertiary education, like governments, parents, students and industry also makes it imperative to assure quality in teaching and learning in general and in English language in particular. However, Afful (2007: 142) observes that English for Academic Purposes (EAP) in Ghana has not undergone any systematic evaluation as in similar programmes in America, the United Kingdom and Australia. In a research conducted by the author in one of Ghana's public universities, he observed that their Communication Skills (the local equivalence of English for Academic Purposes) programme, which started somewhere in 1985, would need a major overhaul because of current realities. The situation in Ghanaian polytechnics is not very different: the Language and Communication Skills syllabus currently in use in polytechnics were published some eleven years ago (NABPTEX, 2001) and are yet to undergo any major review. There is no doubt that some efforts have been made at various times at both regional and national levels for language policy frameworks, but to what extent have they influenced quality enhancement in the EAP discipline in various higher educational institutions in Ghana? As a cross-case study involving four tertiary educational institutions (two public and two private), relevant factors on the quality assurance strategies for teaching and learning in general and EAP in particular are analysed with a view to arriving at findings that would help illuminate an essential area in Ghanaian higher education and also contribute to the general debates on QA and EAP. 


\section{The Four Case Study Institutions}

The four tertiary educational institutions involved in this case study were all established within the last two decades (See Table 4-1, Appendix A), a period which also saw the genesis of the global upsurge in quality assurance activities in higher education circles. These institutions were chosen because of their unique and diverse backgrounds and missions, although they have in common the prime objective of providing service in higher education in Ghana. The University for Development Studies (UDS, Wa Campus) and the Wa Polytechnic (Wa Poly), both public institutions, represent the northern half of the country; while the Catholic University College of Ghana (CUCG) and the Islamic University College, Ghana (IUCG), both of which are private and faith-based, represent the southern sector. The older universities and polytechnics were left out in this study because of the likelihood of the huge volumes of historical data that a research of this kind may generate. A look at the private sector was deemed expedient because, the need for governments to pay more attention to educational quality in Sub-Saharan Africa was partly triggered by the recent increased private sector participation in the provision of tertiary education (Materu 2007). The choice of subject institutions from both the south and northern sectors of Ghana was also informed by strategic reasons. As majority of the students of a given tertiary institution would typically come from its catchment area (environs), it would be interesting to explore socio-linguistic factors likely to affect their language learning. Learners' socio-ethnic backgrounds, without doubt, can impact their language learning negatively, especially in the areas of grammar, mechanics, reading, writing, and speaking (pronunciation). Including Wa Polytechnic in this study was also very strategic because, as tertiary institutions engaged in the production of medium and highly skilled human capital, polytechnics play a critical role in national development yet, not very much is known about their quality assurance functions. The University for Development Studies (UDS), which represents the public universities in this study, was chosen because of its uniqueness as a higher education institution set up in largely rural northern Ghana "to establish a clear conceptual and pragmatic meaning of the concept of quality within its contexts" (Abukari and Corner, 2010: 192). It is hoped that findings from the comparison will represent a balanced view of the QA situation in Ghanaian higher education.

Appendix A

Table 4-1. Institutional Contextual Information \& Factors Influencing Cultures of CaseStudy Institutions

\begin{tabular}{|l|l|l|l|}
\hline Wa Poly & UDS & CUCG & IUCG \\
\hline Small sized & Large sized & Small sized & Small sized \\
\hline $\begin{array}{l}\text { Student population: } \\
1,418 \text { (registered in } \\
\begin{array}{l}2011 / 2013 \text { academic } \\
\text { year) }\end{array}\end{array}$ & $\begin{array}{l}\text { Student population: } \\
12,349 \text { (registered } \\
\text { in the 2011/2012 } \\
\text { academic year) }\end{array}$ & $\begin{array}{l}\text { Student population: 4,180 } \\
\text { (registered in 2011/2012 } \\
\text { academic year) }\end{array}$ & $\begin{array}{l}\text { Student population:800 } \\
\text { (registered in 2011/2012 } \\
\text { academic year) }\end{array}$ \\
\hline $\begin{array}{l}\text { Local population: } \\
107,214\end{array}$ & $\begin{array}{l}\text { Local population: } \\
107,214\end{array}$ & Local population: 123,224 & Local population:1,848,614 \\
\hline $\begin{array}{l}\text { Distance from } \\
\text { Accra:(712km) }\end{array}$ & $\begin{array}{l}\text { Distance from Accra: } \\
\text { (712km) }\end{array}$ & $\begin{array}{l}\text { Distance from Accra: } \\
\text { (373km) }\end{array}$ & $\begin{array}{l}\text { Distance from city centre: } \\
\text { (11km) }\end{array}$ \\
\hline Striving for maturity & Striving for maturity & Striving for maturity & Striving for maturity \\
\hline $\begin{array}{l}\text { i) New campus } \\
\text { ii) some basic teaching } \\
\text { and learning materials } \\
\text { \& equipment still } \\
\text { lacking } \\
\text { iii) students' hostel } \\
\text { project at a standstill }\end{array}$ & $\begin{array}{l}\text { i)New campus; one } \\
\text { of four multi-campus } \\
\text { university } \\
\text { ii) inadequate hostel } \\
\text { facilities, classroom, } \\
\text { and office space } \\
\text { iii) construction } \\
\text { ongoing }\end{array}$ & $\begin{array}{l}\text { i)New campus } \\
\text { ii) inadequate physical } \\
\text { infrastructure for staff \& } \\
\text { student accommodation } \\
\text { and library facilities } \\
\text { iii) construction ongoing }\end{array}$ & $\begin{array}{l}\text { i) New campus } \\
\text { ii) well laid-out and } \\
\text { proportionate to relatively } \\
\text { small student numbers. } \\
\text { iii) less stress on available } \\
\text { basic facilities }\end{array}$ \\
\hline \hline
\end{tabular}


Enhancing Quality in EAP Teaching and Learning: A Case Study of Selected Ghanaian Higher Educational Institutions

Research Questions

The two main research questions guiding this study are:

1. How are quality assurance principles being applied for quality EAP teaching and learning at tertiary level in Ghana?

2. What things are the case study institutions doing differently that can be replicated elsewhere?

Objectives of the Study

The object of this research has been quality and how quality assurance strategies are applied in the teaching and learning of EAP at tertiary level in Ghana. The research is aimed at analysing relevant factors on the quality of teaching and learning in general and EAP in particular. As a general objective, the study seeks to contribute to the quality debate and EAP issues through the findings from the research. Specific objectives of this study are to:

- examine the application of quality assurance and control procedures for quality EAP teaching and learning at tertiary level in Ghana;

- compare QA standards used in EAP teaching/learning in Ghana with the CEFR;

- offer suggestions for enhancing the quality of teaching and learning EAP in a multilingual context.

\section{Contribution to Knowledge}

The idea of quality in education is said to be as old as higher education itself. The 1990s witnessed quality assurance assuming centre stage in higher educational institutions all over the world. Consequently, huge volumes of studies have been undertaken on quality and its assurance in higher education. However, not much work has been done in the area of applying quality concepts to language teaching and learning. This research contributes to knowledge by exploring the application of quality assurance principles in the teaching and learning of EAP in a multilingual context like Ghana's. Considering the pervasiveness of EAP in tertiary educational circles, assuring quality in its teaching and learning is crucial as it cuts across all academic disciplines. One thus expects that the literature would be replete with various research works on that field, but literature on the applicability of quality concepts to language teaching and learning is rather scant. It is even scantier when considered within the contexts of Sub-Saharan Africa in general and Ghana's in particular (Afful, 2007). Indeed, some research projects have been undertaken on quality assurance in education, and others conducted on EAP too, but there seem to be none specifically addressing quality assurance in English language teaching and learning. In a country where English is the only official language and main medium of instruction from upper primary to university level, any research that seeks to examine how quality can be enhanced in the teaching and learning of the language for specific purposes in institutions of higher learning is certainly a worthwhile venture. By exploring the quality assurance systems of four tertiary educational institutions in Ghana within the contexts of their mandates and unique visions, this study identifies the peculiarities of each institutional setting and how these impact their QA strategies. The originality of this study is borne by the fact that it is the first empirical study to explore the application of QA concepts to language teaching in Ghana. The study is also the first of its kind to consider responses made by Ghanaian tertiary educational institutions to EAP teaching and learning from an applied linguistic perspective and from the context of quality assurance. Whether it is in the public or private sectors of education, the demand for quality by stakeholders is considered crucial. Tertiary educational institutions have the responsibility of assuring the public that they are "doing the right things the right way" through teaching and learning to produce quality graduates equipped with relevant skills like communication skills for national development. This study contributes to the quality discourse in general and to provide some specific insights into the QA situation in Ghanaian higher education through language teaching and learning. 


\section{LITERATURE REVIEW}

Over the last four decades the English language has witnessed increasing prominence as an 'academic lingua franca' (Crystal, 1997 and 2003). Similarly, the teaching and learning of English for specific purposes has attracted unprecedented attention. This is manifested in the use of English not only as the leading medium of instruction in tertiary educational institutions, but also as the global language of research and publication. Its envious status as the main international language of communication among professionals has contributed to increased research activity in the broader area of English for Specific Purposes (ESP) and its offshoot, English for Academic Purposes (EAP) (Afful, 2007; Hyland and Hamp-Lyons, 2002; Flowerdew and Peacock, 2001; Swales, 1997; Robinson, 1991). As a specific-purpose-language-teaching course, EAP is distinguishable from English for Occupational Purposes (EOP) through learner type, prospective or continuing student rather than a professional on the job (Robinson, 1991). EAP has a very broad scope that can be categorised under two main divisions: English for General Academic Purposes (EGAP) and English for Specific Academic Purposes (ESAP). While the former involves teaching of language and skills that cut across disciplines, the latter concentrates on imparting relevant skills and language to students from specific fields of study (Dudley-Evans and St. John, 1998). For purposes of illustrating how English language education can be classified according to purpose, the diagram below from Lee (2003) is adopted:

Fig.1: Classification of English Language Education for Different Purposes

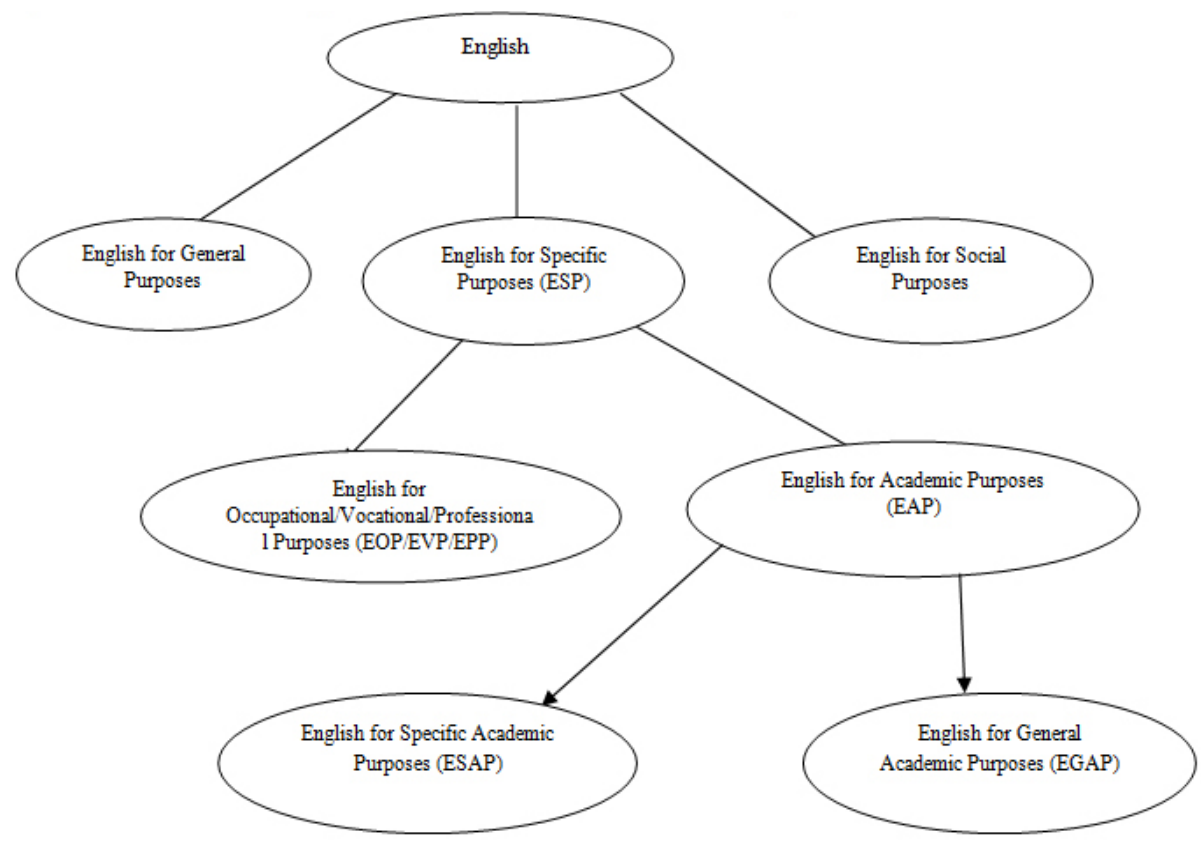

From Lee, 2003: 197

This broad scope of the course adds to its pervasiveness and the possibility of its use for students of diverse academic backgrounds. Another commonly used term associated with EAP is 'Study Skills'. It is considered as "identical in coverage to EAP or as part of EAP" (Ibid). In Ghana, while some tertiary educational institutions teach Study Skills as a stand-alone course, others teach it as part of the EAP course, terming it Language and Study Skills. In this study it is considered as part of EAP, taught to improve students' reading speed, and ability to read for gist; academic writing skills; listening and note-taking skills during lectures, and academic speaking skills. These skills do not preclude grammar teaching though, as students' grammatical difficulties can impact negatively on other skills. According to Mo (2005: 65), "Study skills are not something instinctively acquired but 
Enhancing Quality in EAP Teaching and Learning: A Case Study of Selected Ghanaian Higher Educational Institutions

something consciously learnt." The pervasiveness and relevance of the EAP course in higher educational circles worldwide provides a good reason for conducting this research. The object of this study has been to explore and compare the application of quality assurance principles to EAP teaching and learning in four higher education institutions in Ghana. It is not aimed at prescribing novel principles for quality assurance, but to identify how context-specific QA systems work in the case institutions; what is being done differently there; whether they are replicable elsewhere, and to offer suggestions for quality enhancement. Methods employed in the research include interviews, observation, and administering an appropriate survey to respondents and the subsequent analysis of their responses.

\section{Eap: A Theoretical Background}

English for Academic Purposes (EAP) is a branch of English for Specific Purposes (ESP). It is defined as "teaching English with the aim of facilitating learners' study or research in that language" (Hyland and Hamp-Lyons, 2002:2). EAP programmes are therefore designed to equip students who are undergoing training through the medium of English with the requisite language and related skills. The conventional communication skills that are often targeted are: writing, reading, listening and speaking; while the related language skills include appropriate linguistic tools that enable them in their analysis of the main features of the English language (Quality Assurance Agency for Higher Education, 2007). Usually the teaching content is prepared in such a way that it matches the learner's requirements (Robinson, 1991). Because of the illusiveness of the "general quality" idea, the quality literature stresses that the operational definitions of quality must be specific and "relate to a specific purpose." The "fitness for purpose" concept of quality focuses on customers' needs. Thus, the quality of EAP should be measurable based upon the principle of "fitness for purpose" in the student's own view as well as that of the trainer. As a result, EAP is:

- Goal directed - students learn English because they need it for study and work purposes.

- EAP courses are based on needs analyses - that is, tasks that students have to do in English are clearly spelt out.

- $\quad$ Most EAP programmes have clearly specified time frames - In Ghana, the course is usually done during the first year of tertiary studies and could be described as a foundation course in preparation for academic courses. EAP learners are adults. For instance, research by a technical committee of the Wa Polytechnic Academic Board in 2006 revealed that English was every student's second language (L2); and that students had been studying the language for an appreciable period, with the mean year being 183/4 (Wa Polytechnic, 2006a).

- Students do not necessarily need specialist language - activities the students will engage in constitute the basis for courses.

- A very high level of proficiency may not be required - the need for students to succeed in their aims matters more. (Robinson, 1991: 2-5)

One distinguishing factor that could be added to those cited from Robinson is that unlike other language programmes that require a period of residence abroad, EAP students may not need to travel abroad.

Like many other academic disciplines, EAP has its own issues. For instance, there is the issue of specificity of the concept as to whether students should be taught skills and academic features of language that are common to different disciplines or whether EAP should be focused on specific disciplines (Lis, 2010:184). Coffey (1984) has been acknowledged as the first to distinguish 'common core' and 'subject specific' EAP, while the division of EAP into English for General Academic Purposes (EGAP) and English for Specific Academic Purposes ESAP) has been ascribed to Blue (1988) (Ibid.). Based upon this, EAP has been commonly divided into two branches: EGAP and ESAP. EGAP tends to emphasize listening, speaking, reading and writing as relevant skills associated American Research Journal of English and Literature Page 5 
Enhancing Quality in EAP Teaching and Learning: A Case Study of Selected Ghanaian Higher Educational Institutions

with the day-to-day study activities of students. ESAP on the other hand seeks to help students put into practice skills acquired in EGAP by applying them to actual subject tasks like in understanding lectures, reading texts, or writing essays and or reports. It is interesting to note that the Ghanaian version of EAP combines elements of both EGAP and ESAP as later discussions will reveal. Two questions worth considering at this point are: 1 . What situations then may necessitate the teaching of EAP? 2. Does the distinctiveness of EAP have any implications for QA practices?

\section{Possible Contexts for EAP Teaching}

Different situations may warrant the teaching of EAP. Just like QA, national and institutional contexts play a critical role in determining the content of the programme. Dudley-Evans and St John (1998: 34 - 41) identify four types of situations in which EAP is taught:

- an English speaking country, where international students join tertiary education institutions (e.g. USA, UK, Australia);

- ESL situations, where English is mainly used at all levels of education but in everyday situation national language dominate (e.g. Anglophone countries in Africa, South East Asian countries);

- $\quad$ situations in which only certain subjects are taught in English (i.e. Medicine, Engineering, Science subjects) and the national language has dominant position in the school system (e.g. Middle East);

- ESP situations where subjects are taught in the national language (Latin America, South East Asia, mainland Europe, Scandinavia). (Dudley-Evans and St John, 1998).

EAP teaching in Ghana falls within the second scenario described by the co-authors. As a former British colony, not only is English the official language in the country, it is also the main medium of instruction from primary through tertiary levels of education. EAP, termed locally as Communication/Communicative Skills or Language and Study Skills in some contexts, is a key course taught in tertiary education institutions to help undergraduates acquire relevant academic literacy skills (Afful, 2007). Tertiary students, irrespective of their fields of specialty, take the course even if for a limited time-frame. It is considered as a transitional course to re-orient undergraduates linguistically to metamorphose from the use of high school lingo to tertiary. As a general course that cuts across fields of study, its importance cannot be overemphasized. The next paragraph provides some justification for its choice as the unit of analysis in this study.

\section{Why EAP?}

The choice of EAP as the unit of analysis was informed by its pervasiveness as a course in higher education institutions in Ghana. As the lingua-franca of Ghana, English is used as the medium of instruction from primary through tertiary levels of education. It is an acknowledged fact that in most post-colonial countries indigenous varieties of English have emerged different from British standards. This has led to some scholars wondering what the appropriate EAP model should be in these countries (Kachru, 1988). As Flowerdew and Peacock (2001: 23) rightly observed, though the indigenous variety may enjoy greater currency locally, the international standard would be more useful when it comes to access to international literature, interaction with other academics internationally and publication of their research results in international journals. Locally, we have what is called "Ghanaian English;" however, due to the reasons cited, Standard English is the preferred medium of instruction in Ghanaian HEIs. Globally, the EAP discipline is expanding within universities and other tertiary education institutions. In addition, challenges engendered by globalisation and internationalisation have immensely contributed to the enhancement of the status of English as a language of international diplomacy, business, information technology, and higher education delivery. In the academic environment English has assumed a dominant role as an academic lingua-franca. Hyland (2006) for instance observes the rapid loss of linguistic diversity in academic publications all over the world. By making their online publications available to libraries, English-medium journals are making a greater impact, as researchers are more likely to cite them. 
Enhancing Quality in EAP Teaching and Learning: A Case Study of Selected Ghanaian Higher Educational Institutions

It is estimated that 95\% of all publications in Science Citation Index are English-medium publications. EAP is a panacea for the poor writing skills of most academics whose mother tongue is not English, because as Hyland notes, such academics face the challenge of meeting the rhetorical standards demanded by editors.

Concerns have also been expressed locally and internationally about falling standards in the communicative skills (especially writing skills) of undergraduate students even in Anglophone countries (Fry et al., 2009; Afful, 2007; Jibril, 2003). While Afful reports on the unfortunate phenomenon in Ghana, Jibril also discloses that the situation in Nigeria is none the better. There has been a decline in proficiency in English at all levels of the educational system, with poor communicative competence being the major cause of failure in public examinations both at the secondary and the higher educational levels (Aful, 2007; Jibril, 2003). However, not much has been done on EAP in the field of research. Hamp-Lyons for instance attests that EAP is:

a thriving and important aspect of TESOL that has so far received less attention from researchers than it deserves.... [and is] more complex and potentially problematic than most English language teachers recognize in the beginning of their EAP teaching. (Hamp-Lyons, 2001: 130).

Commenting on the impact of English as a medium of instruction in African higher education, Teferra also observes that language is one of the hidden yet subversive elements that undermines the quality of higher education across Africa. In the literature to date, language is often relegated to the bottom of the list of problems that plague African higher education(Teferra and Altbach, 2003: 111).

Considering its prominence as an instrument of educational delivery, the impact of English language on higher education across the continent cannot be overemphasized. One would therefore expect that when addressing issues that have the potential of compromising the quality of African higher education, language would be one of the most researched areas. Yet, in the body of literature is a yawning gap as it fails to adequately recognise or even discuss the language challenge in order to address issues affecting quality in higher education. This paper aims at exploring the application quality assurance principles in teaching and learning in general and the impartation and impact of the EAP course in particular in Ghanaian higher education. To situate the unit of analysis within the context of the more macro issues of quality and quality assurance, the following question would be considered:

\section{Quality of what? - A lecture? - A lecturer? - A course? - An institution?}

Like any other academic course, EAP instruction is carried out by teacher/teachers in keeping with certain accepted standards and subject benchmarks; within a specific timeframe and institutional context. It is the conscious and collective implementation of the processes and procedures that lead to the eventual achievement of quality learning outcomes. This study would therefore examine how the four case study institutions manage their strategies to guarantee quality EAP, and also how the assurance of the quality of the discipline contributes to higher-quality learning of English among students. It is hoped that the findings would serve the broad purpose of contributing to knowledge and also provide a basis for recommendations for quality enhancement. In order to establish criteria and set standards for EAP teaching and learning, subsequent paragraphs examine the quality literature to determine the potential relevance of different quality concepts and theories to the discipline.

\section{Tools for Ensuring Quality in Language Teaching}

An important component of QA in higher education is the provision of appropriate mechanisms for accessing student feedback and also ensuring that the feedback so derived is acted upon by authorities for quality enhancement. The Grundtvig Partnership (2011) in a twenty-seven-country survey identified observation, assessment, and the possession of appropriate qualifications by teachers as examples of best practices in language teaching for adults in Europe. The partnership observed that QA tools in themselves do not lead to better language teaching and learning unless they are used well. Creating a congenial learning environment and blending it with the use of quality tools is a sure way of attaining a rewarding teaching and learning 
Enhancing Quality in EAP Teaching and Learning: A Case Study of Selected Ghanaian Higher Educational Institutions

experience. Choosing from different kinds of available tools and ensuring that your choice suits your objective, and consciously involving all the major stakeholders: the learners, the teachers and the institution are also steps in the right direction.

Another important mechanism for assuring quality in language teaching is the discussion of marked scripts by teachers with their students after assessments. Nott (2013:4) asserts that "[t]he principal purpose of marking is to provide students with feedback on their performance: marking thus stands at the sharp end, at the point of implementation, of formative assessment." This makes the practice of marking and discussing the scripts afterwards with students an integral part of implementing quality in language teaching. It also affords both teacher and learner an opportunity for improving upon their work. As major players in the use of QA tools to enhance teaching, UNESCO aptly describes teachers as "persons whose professional activity involves the transmitting of knowledge, attitudes and skills that are stipulated in a formal curriculum or programme to students enrolled in a formal educational institution" (UNESCO, 2009: 26). In the context of this study, a "good teacher" is seen as one who skillfully blends the mastery of the course with excellent pedagogy and the right demeanour in class to deliver quality tuition for positive learning outcomes.

\section{Conduciveness of the learning environment vis-à-vis quality of learning experience}

In recent times, one key element in measuring the quality of education has been the student experience. This phenomenon, according to Tricker (2003), is ascribable to the role of students (or their parents) in contributing directly to the cost of their training. The Grundtvig Learning Partnership 2009-2011 has also stressed the need for maintaining a balance between a "conducive" learning environment and the utilisation of "quality assurance" tools. Such tools must as well be suitable ('fit') for the realisation of the institution's objectives. The study also agrees with the assertion that the learning environment is not limited to the physical surroundings or milieu; it also includes "psychosocial" and "service delivery" elements that, in turn, create an enabling social climate for quality learning experience (UNICEF, 2000). The Fund further observes a strong correlation between school infrastructure and other quality dimensions like the availability of instructional material, working conditions for students and teachers and the ability of teachers to undertake certain instructional approaches which all affect the quality of teaching and learning UNICEF (2000: 7). Other research findings equally affirm the existence of a positive relationship between the quality of the school environment and student/teacher attitudes. A classic example cited is a summary of literature review conducted for the University of Georgia by Jago and Tanner (1999) which provides some interesting conclusions by various researchers on the subject:

- Stockard and Mayberry (1992): There is a relationship between the quality of a physical plant or environment and non-cognitive outcomes like better attitudes toward school, and ultimately translate into enhanced academic achievement.

- Ferreira (1995): The state of buildings can have a direct effect on the attitudes of students, their teachers, and parents.

- Christopher (1998): "Human nature makes people feel better about themselves when their surroundings are pleasant."

These views were supported by the UNICEF based on research findings from developing countries like India, Latin America, Botswana, Nigeria, and Papua New Guinea which all found that:

students ... whose schools lacked classroom materials and had an inadequate library were significantly more likely to show lower test scores and higher grade repetition than those whose schools were well equipped"

(Carron and Chau, 1996; Williams, 2000; Pennycuick, 1993 in UNICEF 2000: 7) 
Enhancing Quality in EAP Teaching and Learning: A Case Study of Selected Ghanaian Higher Educational Institutions

Even though some of the studies were conducted in pre-tertiary educational environments, it is obvious that most of the findings also hold true for adult learners and are therefore relevant to the context of this study. After this broad overview of the quality situation, it should be worthwhile examining the application of QA procedures to language education.

\section{Why Apply QA Procedures in Language Education}

Like any field of endeavour, language education must meet the expectations of its stakeholders - learners, parents, employers, the government and society at large. It is therefore essential that relevant standards and criteria are set for assessing the quality of teaching and learning activities. As Heyworth puts it, "in the field of language education there is the need to have a clear and coherent idea of what are "the right things" that we are doing, and procedures for checking that we are "doing things right" " (Heyworth, 2011: 2). Ghana is a multi-lingual country with English as her official language and the main language of politics and law. For the majority of students, English is their L2. EAP is taught in almost all tertiary educational institutions in the country, but unlike in other countries, the reason for its teaching goes beyond just equipping students with the requisite competences in academic English to helping improve upon their general performance in English, which is considered 'abysmal' for most students. The language policy of education in Ghana, though developed with good intentions, has been blamed for this unfortunate situation partly because of its 'checkered history' and partly due to lapses in implementation. The acknowledgement by researchers like Baker (2000) and Lewelling (1991) that the level of first language proficiency can impact positively on second language development and cognitive and academic achievement has been the basis for the policy recommending the use of Ghanaian languages as media of instruction in lower primary (i.e. primary one to three). However, since 1525 there has not been a consistent language policy. While some governments have continued with the full implementation of the policy; others have discontinued it, and rather subscribed to the use of English only in teaching at all levels (Owu-Ewie, 2006). For instance, in 2002 a law was promulgated mandating the use of English language as the medium of instruction from primary one. Owu-Ewie (2006) observes that the problem is not with the policy but its implementation, pointing out that the teachers and learners have not been provided with the needed resources to teach the English language. The mere use of a child's L1 at the lower primary level, he argues, does not guarantee achievement in English language. Citing Carroll (1962), he notes that for a programme to ensure success in L2, it must provide quality instruction and enough opportunities for learning the language, including adequate time. He laments that "as a nation, we have not trained teachers to teach English as a foreign language in a meaningful way and use it for academic purposes in a way that could lead to maximum returns" (Owu-Ewie, 2006:79).

As the application of QA procedures to teaching in general, and to language teaching in particular in Ghana are examined, it is appropriate to take into account the language teaching field of Europe, the origin of the English language, so as to determine how far it can (or cannot) be usefully applied locally. A major QA document: The Common European Framework of Reference for Languages (CEFR) (2001), provides some useful guidelines. First, a brief discussion of the CEFR and its role in enhancing the quality of L2 teaching and learning:

\section{The Common European Framework of Reference (CEFR) for Languages}

The CEFR "provides a common basis for the elaboration of language syllabuses, curriculum guidelines, examinations, textbooks, etc." (Council of Europe, 2001). It evolved as a result of the several issues that emerge when trying to describe levels of language learning, teaching and assessment. In different institutions and among different countries, levels can mean different things. The CEFR's "Global Scale" which ranges from A1 to $\mathrm{C} 2$ thus serves as common reference levels. It describes what a learner can do at six specific levels A1, A2, B1, B2, C1, and C2. A1 and A2 are for the basic user; B1 and B2 for the independent user, and C1 and C2 for the proficient user. These levels match general competency concepts of basic, intermediate, and advanced. Common reference levels are based on a set of "can do" statements describing what a learner is capable of, not what he/ 
Enhancing Quality in EAP Teaching and Learning: A Case Study of Selected Ghanaian Higher Educational Institutions

she cannot do or does wrong. The CEFR describes

- Competencies necessary for effective communication.

- Skills and knowledge related to language learning and competencies.

- Situations (people, place, time, organisation, etc.) and contexts (study, work, social, tourism, etc.) in which communication takes place. (CEF, 2001 in Pearson Longman 2007: 4).

On the relevance of the CEFR in this study, two questions are worth considering:

1. Why should a framework termed "European" be worthy of consideration in a study conducted outside Europe?

2. What is the role of the CEFR in contributing to definition of the object of this study?

First, it should be noted that the word "European" in the Common European Framework does not imply that the framework is meant for persons studying or teaching in Europe alone; neither is it a political or cultural tool intended for the promotion of Europe or European educational systems (Pearson Longman, 2007). Instead, the term refers to European languages, one of which is English, the unit of analysis in this thesis. Furthermore, the CEFR is not a methodology and so does not prescribe a way of teaching. Rather, it serves as a descriptive framework for all language levels, affording language teachers a leeway to achieve new levels of proficiency using a methodology they deem convenient (Pearson Longman, 2007: 6). This makes the CEFR appropriate for and adaptable to language teaching research in Ghana as well.

Second, the object of this study being to explore the application of QA principles in the teaching and learning of EAP at tertiary level in Ghana, the CEFR is worth referring to. As a language programme, EAP aims at equipping tertiary students with relevant competencies for effective academic communication and also prepare them for the world of work. Placing this in the quality context, the Global Scale of the CEFR can be said to have been tailored after the 'zero defect' concept of quality. Helping learners see the value of learning and how attainable their language goals are, also make the scale fit in the 'value for money' concept of quality. Also, the CEFR's capacity of linking curriculum, pedagogy and assessment more closely than before, makes it what has been described as "the single most innovative feature of the CEF" (Little, 2011: 382). According to Little,

"this capacity arises from its action-oriented approach to the description of L2 proficiency. Each "can do" descriptor may be used to specify a learning target, select and/or develop learning activities and materials, and shape the design of assessment tasks" (Ibid.)

Thus, as far as the contribution of the CEFR to defining the object of this study is concerned, the following conclusions could be drawn: i) It might be used to construct the EAP curriculum as the quote from Little 2011 rightly infers; ii) It might be used as a scale (indicator) to measure proficiency levels of students after the EAP course (see Section 2.5.1), and iii) If a test were made and scored in CEF terms also before the course, a measure of value-added might be made. These contributions notwithstanding, there is need to consider the following pertinent questions:

a) Does CEFR really measure EAP-proficiency? (If this is a measure that has validity)

b) Does it measure all of EAP-proficiency?

It is noteworthy that the CEFR does not really measure EAP-proficiency, but rather provides a "self-assessment' grid by which learners can measure their own competencies in all the basic communicative skills - reading, writing, listening and speaking. By the same grid, EAP teachers can also assess the proficiency of their students in the course. The CEFR was designed to provide common standards for the establishing of goals and determining achievement. Besides stating values to be considered in the design and approach to curriculum development, 
it also provides the needed conceptual framework for language teaching, learning and assessment. As a framework that does not prescribe a way of teaching, the CEFR cannot be said to be a methodology. It only provides a descriptive framework for all language levels; affording language teachers a leeway to achieve new levels of proficiency using a methodology they deem convenient (Pearson Longman, 2007: 6).

In defining client needs, the introduction of the CEFR poses the following questions as the basis to consider in need analysis:

- What will they need to do with the language?

- What will they need to learn in order to do what they want?

- What makes them want to learn?

- What sort of people are they?

- What knowledge, skill and experiences do their teachers possess?

- What access do they have to resources?

- How much time can they afford to spend?

(Council of Europe, 2001: 4)

Since the teaching content of EAP is prepared to suit the learner's requirements, it meant that the above needs were taken into account the design of the EAP curricula of the case institutions. Thus, although none of case institutions specifically cited the CEFR, it is evident that the quality standards spelt out in the framework are not absent in their contexts. To ensure that the processes, procedures, and resources at the case study institutions are fit for assuring the quality of the EAP programme it would be important to juxtapose their various course objectives with the Global Scale of the CEFR so as to assess actual student communicative abilities at the end of the EAP course.

\section{Conclusion}

Although quality and QA have been acknowledged as indispensable in teaching and learning, ironically there seem to be no consensus on what these terms really are. Varied opinions have been expressed on the concepts despite their acknowledged importance and long history in higher education. While the literature provides many definitions of 'quality', the "fitness for purpose" idea is adopted as a point of departure in this thesis. Indeed, fitness for purpose may not automatically lead to quality enhancement, but focusing on it is deemed appropriate because if the quality of EAP teaching is assured and made fit for the purpose for which it is taught/ learnt, then quality enhancement is achievable.

The inseparability of the concept of 'quality' from "QA" has also been acknowledged. Though the focus of this study has been on the latter and how its principles impact on the quality of teaching and learning of EAP, it was deemed necessary to discuss the former as well. Whereas "quality" is considered in this study as that inherent attribute of a person, an organisation, a product or a service that makes it better or worse than others of its kind and has the potential of amelioration; "quality assurance" is understood as the continuous and context-specific review, evaluation and re-evaluation of institutions, their systems, and programmes against internally and/or externally agreed expectations about standards. As far as higher education is concerned, QA is an all-encompassing activity involving an institution; its programmes and systems as well as its human resource. QA encapsulates the processes, procedures, and policies aimed at enhancing quality. 'Quality' then is a product of $Q A$.

This review also reveals that even though there is some literature on QA in higher education in Ghana and Africa, there seem to be none specifically on the teaching and learning of EAP - the unit of analysis in this study. 
Similarly, information on quality assurance in private tertiary education institutions in Ghana is rather sparse. It is therefore hoped that by doing a cross-case analysis of the differences between private and public HEIs, this study would help highlight issues pertaining to a hitherto "unresearched" area and also make some more insight to what already exists on managing QA in teaching and learning in Sub-Saharan Africa. Considering its central role in assuring quality in L2 education, the Common European Framework of Reference was also discussed. As the study involves curricular, pedagogical and assessment issues in EAP, the CEFR was considered crucial in this review as these issues constitute its principal features. It was observed that the framework might be used to construct the curriculum; used as an indicator to measure proficiency levels of students after the EAP course; or might be used in making a measure of value-addition.

\section{METHODOLOGY}

With the object of this research being to explore the application of quality assurances strategies in the teaching and learning of English for Academic Purposes (EAP) at tertiary level in Ghana, the study analysed relevant factors on the quality of teaching and learning in general and EAP in particular with a view to contributing to the quality debate and through the research findings, offer some suggestions for enhancement of the quality of teaching and learning EAP in a multilingual context like Ghana's. As a means of soliciting relevant unstructured data from key survey participants: students, lecturers, and administrators for a better appreciation of the local QA phenomenon, the study adopted qualitative tools. However, given the varied contexts of case institutions like the public/private divide, different missions, visions and foci, the study also took some quantitative dimensions. Combining the two methods in this study also lends credence to the assertion that each of them has its own place and strengths in research.

\section{Determining the Sample Size}

The sample for this survey comprised 550 undergraduate and diploma students as well as 17 academic and administrative staff drawn from two public and two private tertiary educational institutions in Ghana. Aiming for a perfect sample size in a typical L2 survey research has been described as "unrealistic or simply not feasible ... in the psychometric sense" (Dornyei 2003: 60). In view of this, the study adopted a sample that was deemed representative enough of the general population of each case institution.

\section{Analysing the Data}

The varied forms of data collected were analysed using version 16.0 of the computer-aided quantitative data analysis software - SPSS for data that were conducive to statistical analysis, while adopting "analytic" strategies to analyse data derived from unstructured open-ended questionnaires. Content analysis is said to be the reviewing "of forms of human communication including books, newspapers, and films as well as other forms in order to identify patterns, themes or biases" (Williams, 2007: 69). The method is designed in such a way that it enables the researcher to identify specific characteristics from the content in human communication. In the process, verbal, visual, behavioural patterns, themes, or biases are explored by the researcher.

EAP deals with the language and related skills that students need to acquire in order to undertake studies in higher education through the medium of English. As such, the teaching content is matched to the learners' requirements (Robinson, 1991). To best appreciate how far this objective is being achieved in Ghanaian higher education circles, the content analysis approach was deemed appropriate for adoption, especially as the study involved quantitative data. As a study involving qualitative methods as well, a naturalistic approach was adopted where necessary. Responses received from the survey were first summarised into coherent categories from which relevant themes were identified and labeled in accordance with some of the QA themes.

\section{Interpretation}

This study involves a multiple-case design. Care was taken in ensuring that evidence provided in the study was convincing enough to the reader. To achieve this, the limits of the cases covered by the study were clearly defined 
Enhancing Quality in EAP Teaching and Learning: A Case Study of Selected Ghanaian Higher Educational Institutions

with the strengths and drawbacks in various methods used also pointed out. Typical of multiple-case studies, this research followed "a replication of logic" (Tellis 1997). Facts were obtained from a variety of sources and conclusions drawn were based on those facts.

\section{DISCUSSION OF RESEARCH FINDINGS}

This section discusses the answers to the research questions individually to be followed by the presentation of general recommendations and suggestions for further research. An attempt is made here to establish the relationships between contexts, quality and quality assurance in the study. This is deemed important not only for the ease of comparison of the cases, but also to help sustain the recommendations that would eventually be made in this study.

\section{Contextual Information and Factors Influencing Cultures of Case Study Institutions}

The contextual material summarized in Table 4-1 under Appendix A outlines the factors that influence the cultures of the case institutions and seeks to provide the needed framework the discussion. It is evident from the table that only one of the case institutions can be considered as large in terms of student population. The case study institutions are all operating from new campuses at their permanent sites, which can hardly be described as having the full complements of facilities for effective teaching and learning. Besides IUCG, construction works are underway at the campuses of the other three case institutions and seem to be progressing at a slower pace at the two public ones - UDS and Wa Poly. Some basic equipment, infrastructure, and teaching and learning materials are still lacking in all the case study institutions. The institutions with smaller numbers as well as the one with comparatively greater student numbers have challenges engendered by circumstances inherently linked to their individual contexts. Their peculiar challenges obviously threaten the realisation of their respective internal QA objectives, as the quality culture of a given HEI does have a close connection with its environment (Harvey and Stensaker, 2008).This observation was confirmed by the responses from the survey participants and interviewees. Although participants from all the case study institutions complained about some inadequacies in existing teaching and learning facilities that militate against the realisation of enhanced quality EAP learning, those from UDS expressed the greatest dissatisfaction with the conduciveness of their general learning environment due to the lack of certain basic facilities. They cited distant lecture venues; congestion and discomfort in classrooms; large class sizes for EAP lessons; inadequate furniture; poor visibility and audibility in class as some of the factors impacting negatively on the quality of their learning experience. Though UDS, (Wa campus) appears to be better endowed in terms of student numbers and thus has a greater potential for higher revenue generation, the reality on the ground does not seem to reflect this status considering the complaints of survey participants about inadequate teaching and learning materials. Writing on the quality dilemmas of UDS, Abukari and Corner (2010) argued that "what seems to be clear is that the financial constraint on the UDS has dichotomized the quality of its knowledge for service slogan into what may be termed 'rhetoric' and 'non-rhetoric' dimensions". Be that as it may, it must be acknowledged that quality assurance is a necessary but expensive enterprise. It is common knowledge that even in times of regular flow of funds from the state, internally generated funds (IGF) have often come in handy to supplement the support received from government and other funding sources for the provision of basic materials and equipment to enhance the quality of teaching and learning. If bigger universities are struggling, one can only imagine what could be happening in the smaller less endowed ones. Low student numbers, as depicted in the summary above, therefore implies low IGFs for the other three smaller case study institutions, namely Wa Polytechnic, CUCG, and IUCG. Factors accounting for the low numbers in the three institutions include: prestige, competition, attractiveness of available course offerings, and the recent insistence by NAB on the possession of a minimum of grade $\mathrm{C} 6$ in requisite core and elective subject areas by applicants to tertiary institutions in Ghana. Overall, 
Enhancing Quality in EAP Teaching and Learning: A Case Study of Selected Ghanaian Higher Educational Institutions

the factors discussed do have a bearing on the cultures of the case institutions. For instance, it is observable from the summaries that all the case HEIs are fairly young and were established in the 1990s and early 2000, the period when the English language was gaining an unprecedented prominence as a global lingua franca, and research into English for Specific Purposes (ESP) was also gathering momentum in academia (Afful, 2007; Hyland and Hamp-Lyons, 2002; Flowerdew and Peacock, 2001; Swales, 1997; Robinson, 1991). Second, their establishment falls within the era when the introduction of formal quality assurance systems into the higher education landscape, globally and in Sub-Saharan Africa in particular, took centre stage. It was also the period of increased private sector participation in the provision of tertiary education (Materu, 2007), one of the main reasons cited for governments seeing the need to pay closer attention to educational quality in the sub-region through the establishment of QA agencies.

It is interesting to note that in the context of this study, the status of the case institutions as young HEIs has very significant implications for internal quality implementation as it can delay the pace of the development of their respective institutional and quality cultures. The interconnection between quality culture and quality assurance processes has also been acknowledged by Harvey and Stensaker (2008). This author agrees with Loukkola and Zhang (2010) in their assertion that the cultural dimension of 'quality culture' comprises "shared values, beliefs, expectations and commitment." In their description of culture as a concept that encompasses all those values that distinguish the educational institution from others, Ng'ang'a et al. (2012) also affirm that the existing culture in an institution is a major determinant of its performance. Therefore, developing and sustaining a strong culture that ensures high performance is always crucial. Under Literature Review, earlier research was cited for having established that besides the broader scope of national context, factors like institutional size, developmental stage, strategic thrusts, blend of organisational politics, and even its peculiar strengths and weaknesses should be taken into account when assessing the QA systems of an institution. These factors, according to Newton (2002: 187), are critical because "they represent a complex combination of constraint and opportunity". From the summary of background information provided in Table 4-1, the observations cited above on the interrelatedness of quality culture and QA present a true reflection of the contexts within which the case study institutions operate.

On what influence their various institutional and quality cultures, CUCG and IUCG - the two private case HEIs in this study, identified strikingly identical factors as they both cited learning outcomes, external expectations and leadership. Unsurprisingly, this study also observed some disparities in their quality cultures: Though both CUCG and IUCG cited "leadership", the latter qualified their notion of the concept as "cosmopolitan". Whereas CUCG considered staff expertise as important in their culture, IUCG did not. Interestingly, the two case public HEIs - Wa Poly and UDS rather than mention factors influencing their quality cultures, identified their mottos as sources of inspiration for their respective cultures. The two public HEIs cited the empowerment of students through the learning process and community service. The main distinctive feature between the two was the UDS' unique educational philosophy which is not akin to the norms of the conventional university - blending academic knowledge with community development skills through its flagship Third Trimester Field Practical Programme (TTFPP). The slight disparities observed in the quality cultures relate to their order of importance based on institutional contexts. This phenomenon of variations in quality cultures of academic institutions due to differences in their contextual features has been described as "a very logical and welcome feature" by Loukkola and Zhang (2010: 10). All the three institutions cited "external expectations" and "quality of assessments/exam results", but whereas CUCG gave first place to "quality of assessment and examination results", IUCG and UDS placed it second and third respectively. "External expectation" was placed third by CUCG and IUCG, but was identified by UDS as the foremost. "Expertise of staff" was identified by both UDS and CUCG as the second most important factor affecting their cultures. Interestingly, only the two PHEIs cited "leadership", with IUCG identifying it as 
the foremost in impacting its culture. Their assertion affirms the observation made by Brundrett and Rhodes (2011) in the literature that the display of leadership and commitment by top and middle-level managers of HEIs is crucial for quality enhancement in higher education. As new universities that are still charting their paths, there is need for visionary leadership for the realisation of quality objectives. The Wa Poly respondents on the other hand stated the factors in a slightly different manner: "acquisition of relevant knowledge, its application to industry, and service to the community." Being an institution that is mandated to provide technical and vocational education at a higher level, this assertion was not surprising. As factors influencing the institution's culture, the process of ensuring that students acquire the relevant knowledge requires good "leadership" and "staff expertise". Ability of students or graduates to apply the knowledge acquired in industry and community service would also pass for "quality assessment and examination results" (performance) on one hand, and "external expectation" on the other.

On standards by which the achievement of quality objectives can be determined, only two of the case institutions (Wa Poly and UDS) responded. The respondents from Wa Poly simply identified "quality" as critical in building and maintaining reputation to win support of the public. As a young institution that is yet to award its own degrees and diplomas and yet having to compete with older and well-established HEIs, identifying "quality" as a watchword is a step in the right direction. The response from UDS tends to be more elaborate. The following are cited as standards guiding the university's QA principles:

- ability of students to apply knowledge acquired in "community entry"

- community dialogue

- extension

- practical tools of inquiry" by the end of their training

Considering the unique academic and pedagogical philosophy of UDS, Abukari and Corner (2010) argue that measuring quality in the UDS context will be dependent on the extent to which teaching and learning there contribute to the achievement of its broad institutional goals spelt out in its mandate. Generally, this overview of the cultures in the four institutions indicates that all of them are young and therefore have nascent quality cultures with external expectations playing a major role in all. Their respective institutional missions or profiles shine through in the differences that were observed next to the large degree of similarity.

How are quality assurance principles being applied for quality EAP teaching and learning at tertiary- level in Ghana?

The primary research question for this study sought from respondents the specific QA strategies adopted in their respective academic environments for quality EAP. A summary of the QA tools and areas of assessment is presented in Table 4-2 under Appendix B. The different tools and areas of assessment are marked " $\mathrm{X}$ " to show which higher educational institution they apply in. The results indicate that the case institutions employ similar tools in their individual internal quality assessment activities. Specific areas assessed are strikingly similar as well, and can be categorized under five broad thematic areas:

- Course presentation;

- Lecturer's bearing in class;

- Mode of delivery;

- Pedagogy; and

- Learning environment

American Research Journal of English and Literature

Page 15 
Enhancing Quality in EAP Teaching and Learning: A Case Study of Selected Ghanaian Higher Educational Institutions

In all the cases, the appraisal (usually employing questionnaires, surveys, or oral interviews) assesses the quality of pedagogy, assessment and research; teaching and learning materials and equipment; and the physical learning environment. "Observation" by deans, heads of department, and students take into account the quality of EAP teachers' pedagogical and/or presentation skills; their punctuality to and regularity in class as well as the performance of their students or graduates.

\section{Appendix B}

Table 4-2. Specific QA Tools and Areas of Assessment

\begin{tabular}{|c|c|c|c|c|}
\hline Institution & Wa Poly & UDS & CUCG & IUCG \\
\hline QA Tool & $\begin{array}{l}\text { Area of Assess- } \\
\text { ment }\end{array}$ & $\begin{array}{l}\text { Area of Assess- } \\
\text { ment }\end{array}$ & $\begin{array}{l}\text { Area of Assess- } \\
\text { ment }\end{array}$ & $\begin{array}{l}\text { Area of Assess- } \\
\text { ment }\end{array}$ \\
\hline \multicolumn{5}{|l|}{$\begin{array}{l}\text { Internal: a) } \\
\text { Observation of } \\
\text { teacher's }\end{array}$} \\
\hline $\begin{array}{l}\text { bearing in class; } \\
\text { self-discipline and } \\
\text { morality }\end{array}$ & $\mathrm{X}$ & $\mathrm{X}$ & $\mathrm{X}$ & \\
\hline $\begin{array}{l}\text { Pedagogical delivery } \\
\text { skills }\end{array}$ & $\mathrm{X}$ & $\mathrm{X}$ & $\mathrm{X}$ & $\mathrm{X}$ \\
\hline $\begin{array}{l}\text { relevance and } \\
\text { practicality of lectures }\end{array}$ & & & $\mathrm{X}$ & $x$ \\
\hline $\begin{array}{l}\text { qualification/ } \\
\text { experience }\end{array}$ & $\mathrm{X}$ & $\mathrm{X}$ & & \\
\hline full-time appointment & & $\mathrm{X}$ & & \\
\hline $\begin{array}{l}\text { punctuality \& } \\
\text { regularity in class } \\
\text { attendance }\end{array}$ & $\mathrm{X}$ & & $\mathrm{X}$ & $\mathrm{X}$ \\
\hline self-expression & $\mathrm{X}$ & & & $X$ \\
\hline $\begin{array}{l}\text { cordiality/ } \\
\text { interactivity }\end{array}$ & $\mathrm{X}$ & & & \\
\hline $\begin{array}{l}\text { ability to teach } \\
\text { to students' } \\
\text { understanding }\end{array}$ & $\mathrm{X}$ & & $\mathrm{X}$ & $\mathrm{X}$ \\
\hline physical appearance & $\mathrm{X}$ & & & \\
\hline $\begin{array}{l}\text { student/graduate } \\
\text { performance }\end{array}$ & $\mathrm{X}$ & & $\mathrm{X}$ & $\mathrm{X}$ \\
\hline \multicolumn{5}{|l|}{$\begin{array}{l}\text { Internal: b) Appraisal } \\
\text { using questionnaires/ } \\
\text { surveys/oral } \\
\text { interviews }\end{array}$} \\
\hline $\begin{array}{l}\text { teacher's bearing in } \\
\text { class }\end{array}$ & $\mathrm{X}$ & & & \\
\hline
\end{tabular}


Enhancing Quality in EAP Teaching and Learning: A Case Study of Selected Ghanaian Higher Educational Institutions

\begin{tabular}{|c|c|c|c|c|}
\hline pedagogy & $\mathrm{X}$ & $\mathrm{X}$ & & $\mathrm{X}$ \\
\hline self-expression & & & $\mathrm{X}$ & $\mathrm{X}$ \\
\hline $\begin{array}{l}\text { punctuality \& } \\
\text { regularity in class; }\end{array}$ & & $\mathrm{X}$ & & \\
\hline $\begin{array}{l}\text { relevance of reference } \\
\text { material }\end{array}$ & & $\mathrm{X}$ & & $\mathrm{X}$ \\
\hline $\begin{array}{l}\text { quality of lecture } \\
\text { notes }\end{array}$ & & & & $\mathrm{X}$ \\
\hline $\begin{array}{l}\text { availability/quality of } \\
\text { teaching and learning } \\
\text { materials (TLMS) }\end{array}$ & & & $x$ & \\
\hline $\begin{array}{l}\text { teacher's qualification } \\
\text { and/or experience }\end{array}$ & & & $\mathrm{X}$ & \\
\hline $\begin{array}{l}\text { student understanding } \\
\text { and performance }\end{array}$ & & $\mathrm{X}$ & & \\
\hline $\begin{array}{l}\text { ability to meet course } \\
\text { deadlines }\end{array}$ & & $\mathrm{X}$ & & $\mathrm{X}$ \\
\hline $\begin{array}{l}\text { practicality of and } \\
\text { relatedness of lecture } \\
\text { to fieldwork }\end{array}$ & & $\mathrm{X}$ & & \\
\hline $\begin{array}{l}\text { quality of students' } \\
\text { assessment and } \\
\text { outcomes }\end{array}$ & & $\mathrm{X}$ & & $\mathrm{X}$ \\
\hline $\begin{array}{l}\text { Conduciveness of } \\
\text { learning environment }\end{array}$ & & $\mathrm{X}$ & & \\
\hline $\begin{array}{l}\text { External: Periodic } \\
\text { Inspections/ } \\
\text { audits; moderation } \\
\text { of assessments; } \\
\text { mentoring }\end{array}$ & & & & \\
\hline $\begin{array}{l}\text { qualification of } \\
\text { teachers }\end{array}$ & $\mathrm{X}$ & $\mathrm{X}$ & $\mathrm{X}$ & $\mathrm{X}$ \\
\hline $\begin{array}{l}\text { quality of student } \\
\text { entry grades }\end{array}$ & $\mathrm{X}$ & $\mathrm{X}$ & $\mathrm{X}$ & $\mathrm{X}$ \\
\hline graduate performance & $\mathrm{X}$ & $\mathrm{X}$ & $X$ & $\mathrm{X}$ \\
\hline $\begin{array}{l}\text { evaluation of TLMS } \\
\text { and equipment }\end{array}$ & $\mathrm{X}$ & $\mathrm{X}$ & $\mathrm{X}$ & $\mathrm{X}$ \\
\hline quality of assessment & $\mathrm{X}$ & $\mathrm{X}$ & $\mathrm{X}$ & $\mathrm{X}$ \\
\hline $\begin{array}{l}\text { conduciveness of } \\
\text { physical learning } \\
\text { environment }\end{array}$ & $\mathrm{x}$ & $\mathrm{X}$ & $\mathrm{X}$ & $\mathrm{X}$ \\
\hline
\end{tabular}


Enhancing Quality in EAP Teaching and Learning: A Case Study of Selected Ghanaian Higher Educational Institutions

An interesting finding made in this study is that, though a significant percentage of the academic workforce of the PHEIs is part-time (with as high as $87 \%$ of lecturers in one case), respondents from the two private case institutions failed to identify the full-time status of lecturers as needful. It was rather the respondents from UDS, a public university that identified it. Ironic though this may seem; it is important to note that this could be what they see as one of their own strengths or 'unique selling points.' The need raised by the UDS respondents for an assessment to consider the ability of the lecturers to link their material to practical and fieldwork is also in keeping with the unique curriculum of that university. This further emphasizes the need for the EAP curriculum of UDS to take into account that university's unique philosophy so as to equip students with the needed skills for effective community work. Regarding external QA, the tools and areas of assessment were virtually the same in all the case study institutions, except for affiliation with older public universities which is a requirement for PHEIs. This similarity was not surprising since that is how they are regulated. It is also obvious that official rules are followed in the practice and recognised by respondents. Periodic inspections or external audits of programmes and quality of equipment and facilities by state-funded external regulatory bodies; moderation of assessments by external peer reviewers; and mentoring constitute the major areas of external influence in all the institutions. Overall, the five thematic areas identified in this study should best be seen as complementary rather than alternatives and have the potential of interrelated tensions reflecting the values and 'power' of the various players.

The Grundtvig Partnership (2009-2011), in a twenty-seven-country survey, identified the use of QA tools like observation, assessment, and ensuring that teachers possess the appropriate qualifications as examples of best practices in language teaching for adults in Europe. That the results of this research corroborate their findings points to the global nature of these tools and their effectiveness for assuring quality in language learning. The slight discrepancies observed in the application of the tools in the various academic environments also confirm the observation that quality management is context-dependent. In agreement with the partners, it is noteworthy that quality assurance tools in themselves do not guarantee better language teaching and learning unless they are used well. Creating a congenial learning environment and blending it with the use of quality tools is a sure way of attaining a rewarding teaching and learning experience. Choosing from different kinds of available tools and ensuring that your choice suits your objective, and consciously involving major stakeholders like the learners, the teachers, and the institution are also steps in the right direction (Ibid). Brennan and Singh (2010) have also asserted the possibility of QA becoming a tool of both attack and defence for different players in the HE sector. They argue that depending on quality and regulatory regime QA could be an avenue for showing others where power lies. That all the case institutions are required to strictly comply with quality regimes imposed by the National Accreditation Board (NAB) and National Council for Tertiary Education (NCTE) regarding the quality of students' entry profiles, personnel (especially academic staff), and facilities is an affirmation of their observation. The PHEIs are, in addition to the above, required to observe other standards set by their mentoring institutions. Non-compliance with the quality regimes could imply the denial of institutional and new programme accreditation or the forfeiture of re-accreditation for existing programmes. The responses of the case study institutions, as far as external assessment is concerned, are therefore more of "compliance" than anything else. Internally, they could be considered as quality control strategies put in place to serve as a filtering mechanism to help confirm the compliance of the institutions with "minimal agreed-upon quality requirements". Despite the varying degrees of dependence on the identified QA tools, all the four institutions in this case study aim at ensuring that the quality of the EAP course fits the purpose for which it was designed and ultimately lead to the transformation of students into empowered citizens in Ghanaian society and economy. 
Enhancing Quality in EAP Teaching and Learning: A Case Study of Selected Ghanaian Higher Educational Institutions

\section{What subject standards and criteria serve as benchmarks for EAP in the case institutions?}

For easy reference in discussing the responses to this sub-question on standards serving as benchmarks for the EAP course in the case study institutions, a summary is presented in Table 4-3 under Appendix C. This is followed by a comparative summary of emphasis in process/outcome distinctions among case study institutions in Table 4-4 under Appendix D.

\section{Appendix C}

Table 4-3. Summary of Standards Serving as Benchmarks for EAP in Case Study HEIs

\begin{tabular}{|c|c|c|c|}
\hline Wa Poly & UDS & CUCG & IUCG \\
\hline $\begin{array}{l}\text { Course Objective: } \\
\text { To develop in learners } \\
\text { basic communication } \\
\text { skills, especially reading } \\
\text { and writing skills. }\end{array}$ & $\begin{array}{l}\text { Course Objectives: } \\
\text { 1. To assist students } \\
\text { improve upon their } \\
\text { skills and competencies } \\
\text { in English as a working } \\
\text { tool for other courses of } \\
\text { study. } \\
\text { 2. To improve the lin- } \\
\text { guistic skills of students; } \\
\text { 'polish' students' English } \\
\text { grammar and usage; and } \\
\text { enhance their writing } \\
\text { skills. }\end{array}$ & $\begin{array}{l}\text { Course Objectives: } \\
\text { 1. To enhance learners' } \\
\text { writing skills and the } \\
\text { proper use of the English } \\
\text { Language. } \\
\text { 2. To improve the } \\
\text { communication } \\
\text { competence of beginning } \\
\text { students in their self- } \\
\text { expression at both } \\
\text { inter-personal and group } \\
\text { relationships. } \\
\text { 3. To assist students } \\
\text { obtain relevant helps } \\
\text { for undergraduate level } \\
\text { studies, goal setting and } \\
\text { time management. }\end{array}$ & $\begin{array}{l}\text { Course Objectives: } \\
\text { 1. To help "bridge the } \\
\text { pre-tertiary gap in } \\
\text { English grammar and } \\
\text { comprehension. } \\
\text { 2. To assist students } \\
\text { with English reading and } \\
\text { writing skills relevant for } \\
\text { university work. } \\
\text { 3. To get students to } \\
\text { develop the skills of } \\
\text { extracting and sorting } \\
\text { information from } \\
\text { multiple sources and } \\
\text { synthesizing them into } \\
\text { coherent arguments } \\
\text { in their essays and } \\
\text { to acquire academic } \\
\text { presentation skills. } \\
\text { 4. To help students } \\
\text { do close attentive } \\
\text { reading and be able to } \\
\text { distinguish main points } \\
\text { from illustrative details. }\end{array}$ \\
\hline Duration:2 semesters & Duration: 1 trimester & Duration:2 semesters & Duration: 7 semesters \\
\hline Total no. of credits: 4 & Total no. of credits: 2 & Total no. of credits: 3 & Total no. of credits: 11 \\
\hline $\begin{array}{l}\text { Requirement: Compul- } \\
\text { sory to all first-year } \\
\text { students }\end{array}$ & $\begin{array}{l}\text { Requirement: Compul- } \\
\text { sory to all first-year } \\
\text { students }\end{array}$ & $\begin{array}{l}\text { Requirement: Compul- } \\
\text { sory to all first-year } \\
\text { students }\end{array}$ & $\begin{array}{l}\text { Requirement: } \\
\text { Compulsory to all first- } \\
\text { year and continuing } \\
\text { students }\end{array}$ \\
\hline
\end{tabular}


Enhancing Quality in EAP Teaching and Learning: A Case Study of Selected Ghanaian Higher Educational Institutions

Appendix D

Table 4-4. Summary Showing Emphasis in Process/Outcome Distinctions by Case Study HEIS

\begin{tabular}{|c|c|c|c|}
\hline Wa Poly & UDS & CUCG & IUCG \\
\hline Process & Process & Process & Process \\
\hline $\begin{array}{l}\text { Students taught to: } \\
\text { i) make notes; } \\
\text { ii) develop reading and } \\
\text { writing skills; } \\
\text { iii) understand conventional } \\
\text { usage; } \\
\text { iii) use the special cases of } \\
\text { verb agreement; } \\
\text { iv) use the punctuation sign } \\
\text { correctly; } \\
\text { v) know the difference } \\
\text { between sentences, clauses } \\
\text { and phrases, and the } \\
\text { structure of a sentence; } \\
\text { vi) comprehend a passage; } \\
\text { vii) summarize a passage; } \\
\text { and understand figures of } \\
\text { speech; } \\
\text { viii) know the conventions } \\
\text { of usage and develop } \\
\text { writing skills }\end{array}$ & $\begin{array}{l}\text { Students taught: } \\
\text { i)subject-verb } \\
\text { agreement; } \\
\text { ii) the writing } \\
\text { process - free writing, } \\
\text { thinking, planning, } \\
\text { gathering information, } \\
\text { drafting the essay; } \\
\text { iii) essay writing - } \\
\text { narrative, descriptive, } \\
\text { expository and } \\
\text { argumentative; } \\
\text { iv) editing - spelling, } \\
\text { punctuation, and } \\
\text { paraphrasing; } \\
\text { v) common errors in } \\
\text { English usage }\end{array}$ & $\begin{array}{l}\text { Students taught: } \\
\text { i) reading, writing, } \\
\text { research, and oral } \\
\text { skills; } \\
\text { ii) basic grammar } \\
\text { rules, syntax, word } \\
\text { usage, vocabulary } \\
\text { enhancement, basic } \\
\text { composition, and } \\
\text { comprehension }\end{array}$ & $\begin{array}{l}\text { Students taught how to: } \\
\text { i)read and critique a } \\
\text { variety of academic essays } \\
\text { in their areas of study } \\
\text { ii) summarize extracts and } \\
\text { essays; iii) simplify texts of } \\
\text { moderate complexity; and } \\
\text { iv) write both explanatory } \\
\text { and argumentative } \\
\text { synthesis of selected texts }\end{array}$ \\
\hline Desired outcomes: & Desired outcomes: & Desired outcomes: & Desired outcomes: \\
\hline $\begin{array}{l}\text { i) Students able to: } \\
\text { make good notes, } \\
\text { ii) develop reading and } \\
\text { writing skills; } \\
\text { iii) understand conventions } \\
\text { of usage; } \\
\text { iv) use special cases of verb } \\
\text { agreement; and use the } \\
\text { punctuation sign correctly; } \\
\text { v) know the difference } \\
\text { between sentences, clauses } \\
\text { and phrases, and the } \\
\text { structure of a sentence; } \\
\text { vi) comprehend a passage; } \\
\text { summarize a passage; } \\
\text { and understand figures of } \\
\text { speech; } \\
\text { vii) make notes and develop } \\
\text { reading skills. }\end{array}$ & $\begin{array}{l}\text { i)Students develop } \\
\text { good writing skills; } \\
\text { ii) comprehend } \\
\text { written English } \\
\text { literature; and } \\
\text { iii) develop oral } \\
\text { English skills }\end{array}$ & $\begin{array}{l}\text { i) Learners' writing } \\
\text { skills and proper } \\
\text { use of the English } \\
\text { Language enhanced; } \\
\text { ii) communication } \\
\text { competence of } \\
\text { beginners in self- } \\
\text { expression at both } \\
\text { inter-personal and } \\
\text { group relationships } \\
\text { enhanced; } \\
\text { iii) relevant helps } \\
\text { for undergraduate- } \\
\text { level studies, goal } \\
\text { setting and time } \\
\text { management } \\
\text { obtained. }\end{array}$ & $\begin{array}{l}\text { i) Gap in pre-tertiary } \\
\text { English grammar and } \\
\text { comprehension bridged; } \\
\text { ii)students acquire } \\
\text { advanced writing skills; } \\
\text { and able to: } \\
\text { ii) identify the appropriate } \\
\text { form of language (i.e. } \\
\text { register) suitable for } \\
\text { different audience types } \\
\text { and purposes; } \\
\text { iii) write with concision } \\
\text { and coherence, using } \\
\text { logical methods of } \\
\text { development; and } \\
\text { iv) construct sentences } \\
\text { that are consistent with } \\
\text { intention and stylistic } \\
\text { choice. }\end{array}$ \\
\hline
\end{tabular}

It is observable from the summary that the compulsoriness of the EAP course cuts across. All the case study institutions have similar objectives for the teaching of the course. They all cite the enhancement of students' communication and linguistic skills with specific mention of reading and writing as the main objective, but tend to be silent on listening and speaking skills. IUCG is the only institution that somehow explicitly refers to 'speaking' in the objectives where it is stated as helping students to "acquire academic presentation skills." From the literature EAP is defined as "teaching English with the aim of facilitating learners' study or research 

Institutions

in that language" (Hyland and Hamp-Lyons, 2002:2). EAP programmes are thus designed to equip students (being trained with English as the main medium of instruction) with the requisite language and related skills. This description perfectly reflects the phenomenon in Ghana and also falls into the second of the four scenarios identified by Duddley-Evans and St. James (1998) for EAP teaching worldwide: ESL situations, where English is mainly used at all levels of education but with national language dominating in everyday situation (e.g. Anglophone countries in Africa, South East Asian countries).The conventional communication skills that are often targeted are: writing, reading, listening and speaking; while the related language skills include appropriate "linguistic tools" that enable them in their analysis of the main features of the English language (Quality Assurance Agency for Higher Education, 2007). Robinson (1991) also observes that the teaching content (of EAP) is usually prepared in such a way that it matches the learner's requirements. In Ghana, English is the official language and is used as the main medium of instruction from upper primary to university level. As rightly captured in the objectives of IUCG, the EAP course in Ghana, among other things, aims at "bridging the pre-tertiary gap" by helping undergraduate students improve upon their grammar, comprehension, writing and speaking skills.

By way of assessment standards for language education, the Common European Framework of Reference for Languages (CEFR) serves as a global reference. In acknowledging the importance of each of the basic communicative skills (reading, writing, listening, and speaking), it provides descriptors ("can do statements") for assessing the quality of student performance at each stage of their linguistic development. Listening and speaking are thus equally important skills that learners would need if they can participate effectively in lectures and group discussions. Active listening is very necessary for student feedback. Good speaking skills also help boost the confidence of students. Besides reading and writing, the ability of students to listen and speak well certainly goes beyond classroom task requirements to include enhancing their competences to cope with the demands of the world of work. It is therefore important that more conscious efforts are made at highlighting these other two skills in the EAP curriculum of case institutions.

As regards course duration and number of credit hours, UDS has the shortest of just a trimester and two credits in the first year; with IUCG having the longest of seven semesters and 11 credits. It was not surprising that respondents from the former institution were among those who advocated for an extension of the EAP course to cover four years. In Wa Poly and CUCG, the course is taken for two semesters each with four and three credits respectively. Teachers and students from these two institutions also advocated for more contact hours for the course.

To analyse the summaries presented in Appendix D on areas of emphasis in the process/outcome distinctions by the case institutions, reference is made to Heyworth's second and third models - 'quality as a process' and 'quality based on results'. In examining how quality principles can be applied in language teaching, Heyworth (2011) proposes four "models" namely:

- quality as client satisfaction

- quality as a process

- quality based on results

- $\quad$ quality based on values

Placing 'quality' in the language teaching context, Heyworth explains that "delivering language courses can be seen as a set of processes: a connected chain from needs analysis, general setting of curriculum aims, defining syllabus, planning lessons, etc." (Ibid.) The description of the QA processes and their application to EAP teaching and learning in the case fits into Heyworth's first model. The processes and procedures outlined earlier in Table 4-2 (Appendix B) and revisited here, were arrived at based on the analysis of the needs of first-year 
Enhancing Quality in EAP Teaching and Learning: A Case Study of Selected Ghanaian Higher Educational Institutions

undergraduates in Ghanaian HEIs. Responses from subject lecturers interviewed at all the case institutions affirmed that majority of their students had course-initial challenges with poor grammar, poor reading and writing skills, and inadequate vocabulary as some of the commonest weaknesses. These areas also constitute the prime issues that the curricula and syllabuses of the case institutions seek to address. Afful (2007) in an earlier study observed that EAP (locally termed Communication Skills), is taught in tertiary education institutions as a means of helping undergraduates to acquire the relevant academic literacy skills. It is considered as a transitional course aimed at re-orienting undergraduates linguistically to metamorphose from the use of high school lingo to tertiary.

The third model which is 'quality based on results' takes into account the efficiency of the process such that these two fundamental questions are addressed: "how much language is learned?" "Is there satisfactory added value in the learning process?" (Heyworth, 2011). From Table 4-4 (Appendix D), the desired outcomes of the processes put in place at all the case institutions are based on the level of achievement of learners in the EAP course. The attainment of enhanced reading and writing skills by learners is identified by all the case institutions. Three of the case institutions (Wa Poly, UDS, and IUCG) identify improved comprehension and self-expression as areas of desirable outcomes. On actual learner achievement, majority of Wa Poly and CUCG respondents rate their general communication and linguistic skills after taking the EAP course as "excellent". Their course teachers acknowledge this improvement, but do not think it is "excellent" as the students claim, and rate the achievement of the general quality objective of the university as average. In a similar learner self-evaluation at UDS and IUCG majority of respondents rated their achievement in the four major areas of communicative competence as "good". Their claims were confirmed by their teachers. While the UDS lecturers went further to rate the achievement of the general quality objective of the university as 50\%; their colleague from IUCG declined to respond. Despite the disagreements between course teachers and their students in some cases over learner achievement, the results show that the overall realization of their QA objectives as far as EAP teaching and learning are concerned is satisfactory.

\section{How does the Common European Framework of Reference for Languages fit into their various local contexts?}

The study found it quite surprising that such a strategic QA framework for language teaching as the CEFR was unknown to almost all the interviewees from the case institutions. In response to research question (d), only one lecturer from Wa Poly admitted to having heard of it, but conceded that he did not know much about the framework. Nonetheless, the case institutions have standards serving as subject benchmarks in their local contexts. These are in the form of course objectives outlined in their curricula and syllabuses for the Language and Communication (EAP) course. At Wa Poly, an interviewee identified the syllabus for Communication Skills and the recommended grading scale of $\mathrm{A}$ to $\mathrm{D}$ at the end of each semester as the main standard for measuring learner achievement. Though not specifically cited by respondents from the other case institutions, the practice is not any different. To determine how the CEFR fits into the contexts of the case institutions would require a juxtaposition of their course objectives and desired outcomes summarized in Tables 4-4 under Appendices D.

The CEFR which evolved as a result of the several issues that surface when trying to describe levels of language learning, teaching and assessment hinges upon four thematic areas:

i. quality based on client satisfaction

ii. quality as a process

iii. results-based quality assurance

iv. quality and values 
Enhancing Quality in EAP Teaching and Learning: A Case Study of Selected Ghanaian Higher Educational Institutions

As Heyworth (2011:17) observes, "the different models are not mutually exclusive, and in most environments are all present in some way." In defining client needs, the introduction of the CEFR poses the following questions as the basis to consider in need analysis: "Language learning activities are based on the needs, motivations, and characteristics of learners." (Council of Europe, 2001: 4). As discussed in earlier, the above were some of the considerations that went into the design of the EAP curricula of the case study institutions. Thus, although none of the four case institutions specifically cited the CEFR, it is evident that the quality standards spelt out in the framework are not absent in their context. It was noted that because of the illusiveness of the 'general quality' idea, the quality literature stresses that the operational definitions of quality must be specific and "relate to a specific purpose" and that the "fitness for purpose" concept of quality focuses on "customer needs". It was argued that in view of this, the quality of EAP should be measurable based upon the principle of "fitness for purpose" in the student's own view as well as that of the trainer. As a result, the teaching content is usually prepared in such a way that it matches the learner's requirements (Robinson, 1991). This, as well as the characteristics identified below by Robinson, also hold true for the EAP course. It is observable that in all the case institutions the EAP course is:

- "Goal directed" - students learn English because they need it for study and work purposes.

- "EAP courses are based on needs analyses" - In all the case institutions, tasks that students have to do in English are clearly spelt out.

- "EAP programmes have clearly specified time frames" - In all the case institutions (except at the IUCG where it is taken for four years), the course is done during the first year and could be described as a foundation course in preparation for academic courses.

- "EAP learners are adults."

- Students do not necessarily need specialist language - activities the students will engage in constitute the basis for courses.

(Robinson, 1991: 2-5)

\section{What things are the case study institutions doing differently that can be replicated elsewhere?}

In response to research Question (2), the case study institutions identified many practices that contribute to the enhancement of the quality of EAP teaching and learning within their various contexts. It is clear that though the practices are almost identical for all the case institutions, the degree of reliance on specific ones varies from institution to institution. This goes to affirm the general observation in the literature that QA is context-specific (Mishra, 2006).While Wa Poly and CUCG identify quality pedagogy as the most important ingredient for ensuring quality EAP teaching and learning, IUCG and UDS consider it as the second and third most important factors respectively. The use of performance enhancement tools and mode of delivering the course are rather deemed foremost in their respective contexts. Both UDS and CUCG cite the quality of course presentation as the second most important factor in enhancing the EAP teaching and learning. The former case study institution however puts this factor at par with teacher's bearing in class. Like CUCG, Wa Poly identifies teacher's bearing as least important in ensuring quality in EAP teaching and learning. Wa Poly goes on to rate the use of performance enhancement tools second; course presentation as third; and mode of delivery as the fourth most important practices. In the context of CUCG, use of performance enhancement tools is rather rated the third most important practice. Interestingly, neither CUCG nor IUCG cites mode of delivery in their responses.

Overall, it is observable that the practices identified by the case institutions are not novel per se and thus may not pass fully for the "uniqueness" tag. It must be acknowledged that these practices are not very different from 
those used in similar settings for enhancing the quality of teaching and learning of other disciplines. However, the innovations adopted by some of the case study institutions are worth noting for possible replication in other tertiary educational institutions offering EAP. On course duration, for instance, IUCG spreads out the EAP course to cover the four years of undergraduate studies instead of the one-year compulsoriness of the course in the other three case study institutions. This affords learners and teachers ample time to cover relevant topics in the course. According to Gillet (1996) and Jordan (2002), in other jurisdictions like the United Kingdom, EAP is generally considered a pre-sessional course with the length ranging from two weeks to one year. In the context of the case study institutions, where English is the L2 of almost every student, and where the foundation of the majority in English language is considered "poor", an extension of the length of the EAP course to two or more years as proposed by participants in this study would help enhance the quality of teaching and learning the course. Also, IUCG's example of breaking larger classes into smaller groups for EAP lessons for effective interaction between the teacher and learners, could be replicated elsewhere, especially the UDS where class sizes for the course can sometimes be as high 1,500 students.

\section{CONCLUSIONS}

This research contributes to knowledge by exploring the application of quality assurance strategies in the teaching and learning of EAP at tertiary level in Ghana. Its main contribution is fact-finding about the different HEIs and their QA practices. Considering the pervasiveness of EAP in tertiary educational circles, assuring quality in its teaching and learning is crucial, especially in a multi-lingual country like Ghana where English is the only official language and the main medium of instruction from upper primary to university level is crucial for quality learning outcomes. As a research that examined how the quality of teaching and learning of English language for specific purposes in institutions of higher learning can be enhanced, this study is certainly significant. Its significance was taken a step further when the study highlighted the importance of an indispensable-yet-little-heard-of language teaching and learning resource like the CEFR in EAP curriculum design and assessment. Through its cross-case analysis of QA strategies in the public and private sectors of higher education in Ghana, the study contributes to the identification of the differences between the two sectors as regards the enhancement of the quality of EAP teaching and learning. The study also re-echoes the importance of the "student voice" in QA strategies in improving the quality of the teaching and learning EAP. It provided a rare opportunity for EAP students to air their views on a wide range of QA-related issues including the need for:

- adapting existing pedagogies by adopting a more interactive and student-centred approach to EAP learning;

- EAP teachers to be full-timers and masters of their field; approachable and encouraging;

- enhancing the physical learning environment through the provision of quality modern teaching and learning materials;

- reviewing the EAP curriculum regularly and,

- $\quad$ extending the course duration for EAP to a minimum of two years.

Undoubtedly, these findings are significant as they contribute to both policy and scholarship. This study helps re-emphasize the significant role of the student as a major player in the QA process. Sadly, however, it is observable that oftentimes the fear of being victimised makes the student remain silent about genuine QA grievances relating to processes and procedures that could enhance the quality of EAP. Quality assurance gives a voice to these key stakeholders - students. Thus, if their voices are heard, then that can contribute to real quality enhancement. In a multi-lingual environment like Ghana's where English is the L2 of most students, the American Research Journal of English and Literature Page 24 
Enhancing Quality in EAP Teaching and Learning: A Case Study of Selected Ghanaian Higher Educational Institutions

tendency of linguistic intimidation is high. Encouragement rather than intimidation should therefore be the watchword if the quality of EAP learning is to be enhanced.

Overall, taking the QA literature, most of which was developed in Europe, and testing it in an entirely different context (i.e. Ghana) and specifically with EAP further affirms the importance of this study. Tertiary educational institutions have the responsibility of assuring the public that they are 'doing the right things the right way' through teaching and learning to produce quality graduates equipped with relevant skills like communicative skills in English for national development. Thus, another significance of this study lies in its contributing to the quality discourse in general and providing specific insights into the QA situation in the Ghanaian higher education landscape through English language teaching and learning.

\section{Future Research}

As far as future research is concerned, an area that would make interesting investigating is the role of the other players - government, parents, and employers in contributing to quality assurance and the enhancement of EAP teaching and learning in the case institutions or other similar settings. The issue of customer satisfaction touched on by this study, could be explored further in another study. Similarly, the subject of establishing the "effectiveness" of QA mechanisms at ensuring quality EAP in Ghana could also be explored further as the material of this study was not sufficient for an in-depth study on it. Conducting a research that would assess the ability of students or graduates to apply the skills acquired in English language or EAP course in solving everyday communication problems in the real world of work would be an equally worthwhile intellectual venture. It would also be interesting if the other facets of English for Specific Purposes (ESP) like Secretarial English and Business Communication are researched into to ascertain their effectiveness in enhancing learner's communication and linguistic skills in their various fields of study. Another interesting research project would be to evaluate the impact of the socio-economic backgrounds of learners on the quality of their EAP learning experience.

\section{RECOMMENDATIONS}

This section makes general recommendations based on observed challenges regarding the application of quality assurance principles to enhance the quality of EAP teaching in the case study HEIs' processes. These recommendations follow from the research findings and the responses to the research questions from each of the case study institutions. Five broad areas were identified as requiring urgent intervention to enhance the quality of teaching and learning of EAP in the case study institutions. These include: improvement of the quality of teaching and learning materials, and the general learning environment; periodic review of the EAP curriculum and extension of the course duration; adoption of appropriate pedagogy and the development of institutional quality assurance frameworks.

\section{Providing Quality Teaching and Learning Materials and Environment}

In all the case study institutions, respondents complained about the quality of teaching and learning materials and the general physical learning environment. To ensure the availability of quality TLMs, equipment, and infrastructure, government and funders (of the PHEIs) should increase budget allocation to the institutions. More spacious lecture halls; libraries; hostel facilities; relevant books; ICTs and other resources on EAP should be provided to enhance the teaching and learning of the discipline. Wa Poly and UDS are both public and depend on IGF and government subvention. As new HEIs located in a rural and asset-poor environment, Government should consider giving the two institutions some special concession by increasing their annual budget allocations substantially to supplement funds generated internally. Funders of CUCG and IUCG should equally step up their budget allocations to the two private institutions. Considering the invaluable contribution 
Enhancing Quality in EAP Teaching and Learning: A Case Study of Selected Ghanaian Higher Educational Institutions

they are making to the provision of quality tertiary education in the country, the Government of Ghana should also consider increasing the annual allocations from the Ghana Education Trust Fund (GETFund) to private HEIs like CUCG and IUCG.

\section{Curriculum Review and Extending EAP Course Duration}

The study noted that none of the case study institutions made use of the Common European Framework for Languages (CEFR) as a tool for assuring the quality of EAP. It was also observed that a vital QA strategy like curriculum review was not a regular feature in the institutions involved in this study. It is therefore recommended that Ghanaian HEIS adopt the CEFR in their development of EAP curricula, pedagogy and assessment. The EAP curricula currently in use in Ghana tend to be silent on learner autonomy, which the CEFR emphasizes. In this technological age, it is quite surprising that the various EAP curricula are silent about the use of ICT, especially using of Power Point, teleconferencing and communicating via email. If the CEFR is considered a bit out of date because, besides mentioning email and online or offline computer conferences, it fails to refer to texting or the internet, then one can imagine the gravity of the complete silence of the EAP curricula on ICT use (Little 2011:385). In revising their curricula, it would be important for the case study institutions to include training for EAP students to acquire relevant communicative skills in these areas. Another interesting theme that tends to emerge in this study is that whereas the CEFR, through its set of "can-do" statements, seeks to describe the actual abilities or acquired skills of a learner at some specific levels of language study; the objectives of the EAP syllabi of Ghanaian HEIs tend to emphasize the desired instead - i.e. what the student "should be able to do" by the end of the course. On course duration, the study observed that with the exception of IUCG which allots ample time (seven semesters) for EAP, Wa Poly, UDS and CUCG did not have enough time for the course. It is therefore recommended that those three case study institutions consider extending the current length of the course to at least two years. The study noted that UDS has the shortest duration and should reconsider an increase in the number of contact and credit hours for EAP so that students can have enough time for the course.

\section{Adopting Effective Teaching Approaches and Curriculum Review}

On the most effective teaching approach for EAP in the case study institutions, it is recommended that they adopt an approach that takes into account the learning preferences of their students and approaches that are in keeping with the educational policies of Ghana and best practices in the tertiary sector in the country and elsewhere (Gillet, 2014). Rather than stick to one approach, the case institutions should combine studentcentred approach, which some said they were already using, with a teacher-centred approach so students can benefit from the positive sides of both methodologies. This study found that respondents from all the four case study institutions advocated the review of their existing EAP curricula. It is recommended that the curricula, especially the one used by Wa Poly which is over twelve years old, be reviewed to reflect current needs identified through a survey like this. Introducing phonetics, spoken English and reading tasks into the curriculum would help students get over difficulties emanating from their L1s and consequently improve their pronunciation and their confidence in reading and speaking. EAP teachers should also be encouraged to exhibit a positive bearing in class to create the necessary conducive social climate for student-teacher interaction. They should also display excellent pedagogical and delivery skills, as well as good self-expression.

\section{Developing an Institutional QA Policy}

It is also recommendable that IUCG develop a QA policy and establish a unit to coordinate QA activities. Wa Poly should also restart the annual student-teacher appraisal which has stalled since 2008.The polytechnic should also institute the internal peer review of questions before they are sent to NABPTEX for moderation. 
Enhancing Quality in EAP Teaching and Learning: A Case Study of Selected Ghanaian Higher Educational Institutions

\section{REFERENCES}

Abukari, A. and Corner, T. 2010. "Delivering higher education to meet local needs in a developing context: The quality dilemmas?" Quality assurance in higher education. 18(3): 191 - 208.

Afful, J. B. A. 2007. Academic Literacy and Communicative Skills in the Ghanaian University.Nebula 4(3) 141 - 159.

Baker, C. 2001. Foundations of Bilingual Education ( $3^{\text {rd }}$ Ed.) Clevedon: Multilingual Matters Ltd.

Brennan, J. L. and Singh, M. 2010. Playing the Quality Game: Whose Quality and Whose Higher Education? In Diana Rhoten and Craig Calhoun (Ed.) Knowledge Matters: The Public Mission of the Research University, New York: Columbia University Press.

Brown, H. D. 2007. Principles of Language Learning and Teaching. $5^{\text {th }}$ Ed. New York: Pearson Longman.

Brundrett, M. and Rhodes, C. 2011.Leadership for Quality and Accountability in Education. Oxon: Routledge.

Council of Europe. 2011. Common European Framework of Reference for Languages http://www.coe.int/t/dg4/ linguistic/Source/Framework_EN.pdf Accessed: 22/09/2011.

Council of Europe. 2001. Common European Framework of Reference for Languages. Strasbourg: Language Policy Division.

Crystal, D. 2003. English as a Global Language. $2^{\text {nd }}$ Edition. Cambridge: Cambridge University Press.

Dornyei, Z. and Taguchi, T. 2010. Questionnaires in Second Language Research: Construction, Administration, andProcessing. $2^{\text {nd }}$ Edition. London: Routledge/Taylor Francis.

Dudley-Evans, T. and St. John, M. J. (1998). Developments in English for Specific Purposes. Cambridge: Cambridge University Press.

Flowerdew, J. and Peacock, M. 2001. (Eds).Research Perspectives on English for Academic Purposes. Cambridge: Cambridge University Press.

Fry, H., Ketteridge, S. and Marshall, S. (Eds.) 2009. A Handbook for Teaching and Learning in Higher Education: Enhancing Academic Practice, $3^{\text {rd }}$ Ed. London: Routledge

Gillet, A. 1996, 2000. What is EAP? IATEFL ESP SIG Newsletter, 6, 17-23.

Grundtvig Learning Partnership. 2011. Quality in Language Teaching for Adults: Guidelines for Quality in Language Teaching and Learning. Available at:http://www.files.adulteducation.at/uploads/Guidlines.pdf Accessed: 03/04/12

Harvey, L. and Stenstaker, B. 2008. Quality Culture: Understandings, Boundaries and Linkages. European Journal of Education, 43(4): 427 - 442.

Heyworth, F. 2011. Concepts of Quality. http://archive.ecml.at/mtp2/qualitraining/quality/english/framework/ FH1 Accessed 17/10/11.

Hyland, K. and Hamp-Lyons, L. 2002. EAP: Issues and Directions. Journal of English for Academic Purposes. 1(2002) $1-12$.

Hyland, K. 2006. English for Academic Purposes: An Advanced Resource Book. London: Routleddge.

Jago, E. and Tanner, K. 1999. "Effects of the School Environment on Student and Teacher Attitudes."For the University of Georgia. Available at: http://sdpl.coe.uga.edu/researchabstracts/attitudes.html Accessed: $26 / 10 / 12$.

American Research Journal of English and Literature Page 27 
Enhancing Quality in EAP Teaching and Learning: A Case Study of Selected Ghanaian Higher Educational Institutions

Jibril, M. 2003. Nigeria: Language and Curriculum. In Teferra, D. and Altbach, P. G. (Eds.): African Higher Education: An International Reference Handbook. Indiana: Indiana University Press.

Jordan, R. R. 2002. English for Academic Purposes: A Guide and Resource Book. Cambridge: Cambridge University Press.

Lee, C. H. 2003. "College English for Academic Purposes: A Brief Overview of Theory and Application." Journal of General Education. Vol. 12: 193-207.

Lewelling, V. W. 1991. Academic Achievement in Second Language. Eric Clearinghouse on Languages and Linguistics.Washington, D.C. (ERIC Document Reproduction Service No.ED 329130).

Lis, A. 2010. English for Academic Purposes as a Tool for Internationalisation. Bydgoszcz: WyzszaSzkola Gospodarki. Fads

Loukkola, T. and Zhang, T. 2010.Examining Quality Culture: Part 1 - Quality Assurance Process in Higher Education Institutions. Brussels: European University Association.

Materu, P. 2007. Higher Education Quality Assurance in Sub-Saharan Africa: Status, Challenges, Opportunities, and Promising Practices. World Bank Working Paper No. 124. Washington: World Bank.

Mishra, S. 2006. Quality Assurance in Higher Education: An Introduction. Vancouver: Commonwealth of Learning.

Mo, H. 2005. "A brief review of English for Academic Purposes (EAP)." US-China Foreign Language, 3(7): 62- 67.

Ng'ang'a, M. J. and Nyogesa, W. J. 2012. The Impact of Organisational Culture on Performance of Educational Institutions. International Journal of Business and Social Science.3 (8): 211-217.

National Board for Professional and Technician Examinations, 2001. Higher National Diploma in Secretaryship and Management Studies: Revised Syllabus. Accra: NABPTEX.

Newton, J. 2002. "Barriers to Effective Quality Management and Leadership: Case Study of Two Academic Departments." Higher Education. 44: 185 - 212.

Nott, D. 2013. Marking Students' Work: Principles and Practice. Available at; https://www.llas.ac.uk/resources/gpg/2956 Accessed 07/11/14.

Pearson Longman. 2007. CEF: Teacher's Guide to the Common European Framework. http://www.longman.com/cef Accessed: 22/09/2011.

Owu-Ewie, C. 2006. The language Policy of Education in Ghana: A Critical Look at the English-only language policy. Selected proceedings of the $35^{\text {th }}$ Annual Conference on African Linguistics. Mugane et al. (Ed.) 75 85. Somerville, MA: Cascadilla Proceedings Project.

Quality Assurance Agency for Higher Education, 2007. Subject Benchmark Statement on Language and Related Studies. Available at www.qaa.ac.uk Accessed 05/06/12.

Robinson, P. 1991. ESP Tday: A Practitioner's Guide. London: Prentice Hall

Swales, J. M. 1997. “English as Tyrannosaurus Rex.” World Englishes. 16(3): 373 - 382.

Teferra, D. and Altbach, P. G. (Eds.) 2003: African Higher Education: An International ReferenceHandbook. Indiana: Indiana University Press.

Tellis, W. 1997. Introduction to case study. In the qualitative report, Vol. 3, No. 2 July 1997 http://www.nova. edu/ssss/QR/QR3-2/tellis1.html 
Enhancing Quality in EAP Teaching and Learning: A Case Study of Selected Ghanaian Higher Educational Institutions

Tricker, A. 2003. Students Expectation: How Do We Measure Up? Available at: http://inter-disciplinary.net/ati/ education/ioe/ioe2/tricker\%20paper.pdfAccessed 29/01/13.

UNESCO. 2009. Education Indicators: Technical Guidelines. Paris: UNESCO Institute for Statistics.

UNICEF. 2000. Defining Quality in Education. New York: United Nations Children's Fund, Programmes Division.

Vlasceanu, L. and Grunberg, L. and Parlea, D. 2007. Quality Assurance and Accreditation: A Glossary of Basic Terms and Definitions. Bucharest: For UNESCO.

Wa Polytechnic. 2006. "An Investigation into the Causes of Poor Performance of Students in Communication Skills": A Report Submitted by the Communication Skills Committee to the Academic Board.

Williams, C. 2007. Research methods. Journal of Business and Economics, 5(2) 65 - 72, March 2007.

Citation: Solomon Ali Dansieh, "Enhancing Quality in EAP Teaching and Learning: A Case Study of Selected Ghanaian Higher Educational Institutions." American Research Journal of English and Literature, vol 3, no. 1, 2017, pp. 1-29.

Copyright (c) 2017 Solomon Ali Dansieh, This is an open access article distributed under the Creative Commons Attribution License, which permits unrestricted use, distribution, and reproduction in any medium, provided the original work is properly cited. 